\title{
St. Jude Stage II Childhood Non-Hodgkin Lymphoma AJCC v8
}

National Cancer Institute

\section{Source}

National Cancer Institute. St. Jude Stage // Childhood Non-Hodgkin Lymphoma A/CC v8. NCI Thesaurus. Code C141219.

Stage II: A single tumor (extranodal) with regional node involvement. Two or more nodal areas on the same side of the diaphragm. T wo single (extranodal) tumors with or without regional node involvement on the same side of the diaphragm. A primary gastrointestinal tract tumor, usually in the ileocecal area, with or without involvement of associated mesenteric nodes only. (from AJCC 8th Ed.) 